\title{
Early Miocene vegetation across eastern Africa as reconstructed from phytolith data
}

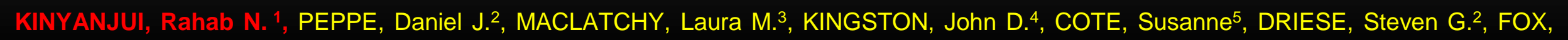
David L. ${ }^{6}$, JACOBS, Bonnie F.7, LEHMANN, Thomas ${ }^{8}$, LUKENS, William E. ${ }^{9}$, ROSSIE, James B. ${ }^{10}$ and MCNULTY, Kieran P. ${ }^{11}$

(1)Earth Sciences Department, National Museums of Kenya, P.O Box 40658-00100, Nairobi, 254, Kenya,

(2)Terrestrial Paleoclimatology Research Group, Department of Geosciences, Baylor University, One Bear Place \#97354, Waco, TX 76798,

(3)Department of Anthropology, University of Michigan, Ann Arbor, MI 48109,

(4)Department of Anthropology, University of Michigan, 101 West Hall, 1085 S. University Ave, Ann Arbor, Ml 48109-1107,

(5)Department of Anthropology and Archaeology, University of Calgary, Calgary, AB 2N 1N4, Canada,

(6)Department of Earth Sciences, University of Minnesota, Minneapolis, MN 55455,

(7)Department of Geological Sciences, Southern Methodist University, P.O. Box 750395, Dallas, TX 75275-0395,

(8)Abteilung Paläoanthropologie und Messelforschung, Forschungsinstitut und Naturmuseum Senckenberg, Senckenberganlage 25, Frankfurt, D-60325, Germany,

(9)Terrestrial Paleoclimatology Research Group, Department of Geosciences, Baylor University, Waco, TX 76798,

(10)Department of Anthropology, Stony Brook University, Stony Brook, NY 11794,

(11)Department of Anthropology, University of Minnesota, 395 Hubert H. Humphrey Center, 301 19th Avenue South, Minneapolis, MN 55455. 


\section{Introduction}

- East Africa, is one of the well known regions in the world for rich in prehistoric localities, preserving hominoid and hominid species dating back to early Miocene period.

- Numerous paleontological and geological studies have been carried out from these localities, with effort to understand the evolution pattern of primates and other mammals.

- However, to clearly understand this, it is paramount to understand the paleoenvironments which these faunal communities interacted with.

- So far, variety of habitats have been suggested by various proxies such as: stable isotopes, eco-morphology, paleopedology among others.

- Some of these proxies indicate presence of $\mathrm{C}_{4}$ plants on the paleolandscapes and often has been disputed due the timing of expansion of grasslands around $10 \mathrm{Ma}$. Nevertheless, this do not rule out the possible appearance of $\mathrm{C}_{4}$ grasses prior to this period.

- This study analysed fossil phytoliths (plants silica) recovered from early Miocene localities to reconstruct vegetation structure, determine how they vary between sites and in particular determine whether $\mathrm{C}_{4}$ grasses were part of the vegetation component of the early Miocene landscapes 


\section{Aim and objectives}

- This project is part of a larger REACHE (Research on East African Catarrhine and Hominoid Evolution) project which seeks to understand early Miocene paleoenvironments and paleoclimates and their role in shaping Hominoid and Hominid evolution trajectories.

- Phytolith study is one of the multi-proxies approach, aimed to determine vegetation component of the paleoenvironments and how they varied through time and across space during the said period.

- Phytoliths are particularly important in identifying different grass subfamilies which grow under different habitats with specific environmental/climatic parameters. Panicoideae $\mathrm{C}_{4}$ grasses thrive under warm and moist conditions, Chloridoideae $\mathrm{C}_{4}$ grasses thrive under hot and dry conditions, Arundinoideae $\mathrm{C}_{4}$ grasses in wetlands and swampy environments. Pooideae grasses in tropical Africa are mainly found in high altitudes and therefore reflect cool and moist climates.

- Paleosol samples were collected from all the localities with guidance from key geologists involved in the project Field work 


\section{Why phytoliths?}

- Initial samples showed phytoliths are preserved in feasible amounts and the assemblage can be reliable to estimate the vegetation composition/structure of early Miocene environments.

- Phytoliths are particularly important in identifying different grass subfamilies which grow under different habitats with specific environmental/climatic parameters as follows:

- Panicoideae $\mathrm{C}_{4}$ grasses thrive under warm and moist conditions,

- Chloridoideae $\mathrm{C}_{4}$ grasses thrive under hot and dry conditions,

- Arundinoideae $\mathrm{C}_{4}$ grasses in wetlands and swampy environments,

- Pooideae grasses in tropical Africa are mainly found in high altitudes and therefore reflect cool and moist climates. 


\section{Research localities}

- Phytoliths are often used as a proxy to determine and reconstruct past vegetation composition and structure, in addition to providing insights about past climates.

- Depending on depositional environments, both local and regional vegetation structure can be reconstructed.

- Preliminary phytolith data from six early Miocene localities; three in Uganda (Bukwa, Napak and Moroto II) and three in Kenya (Karungu, Tinderet, and West Turkana).

- These sites date between ca. 21.2 Ma and ca.16 Ma.

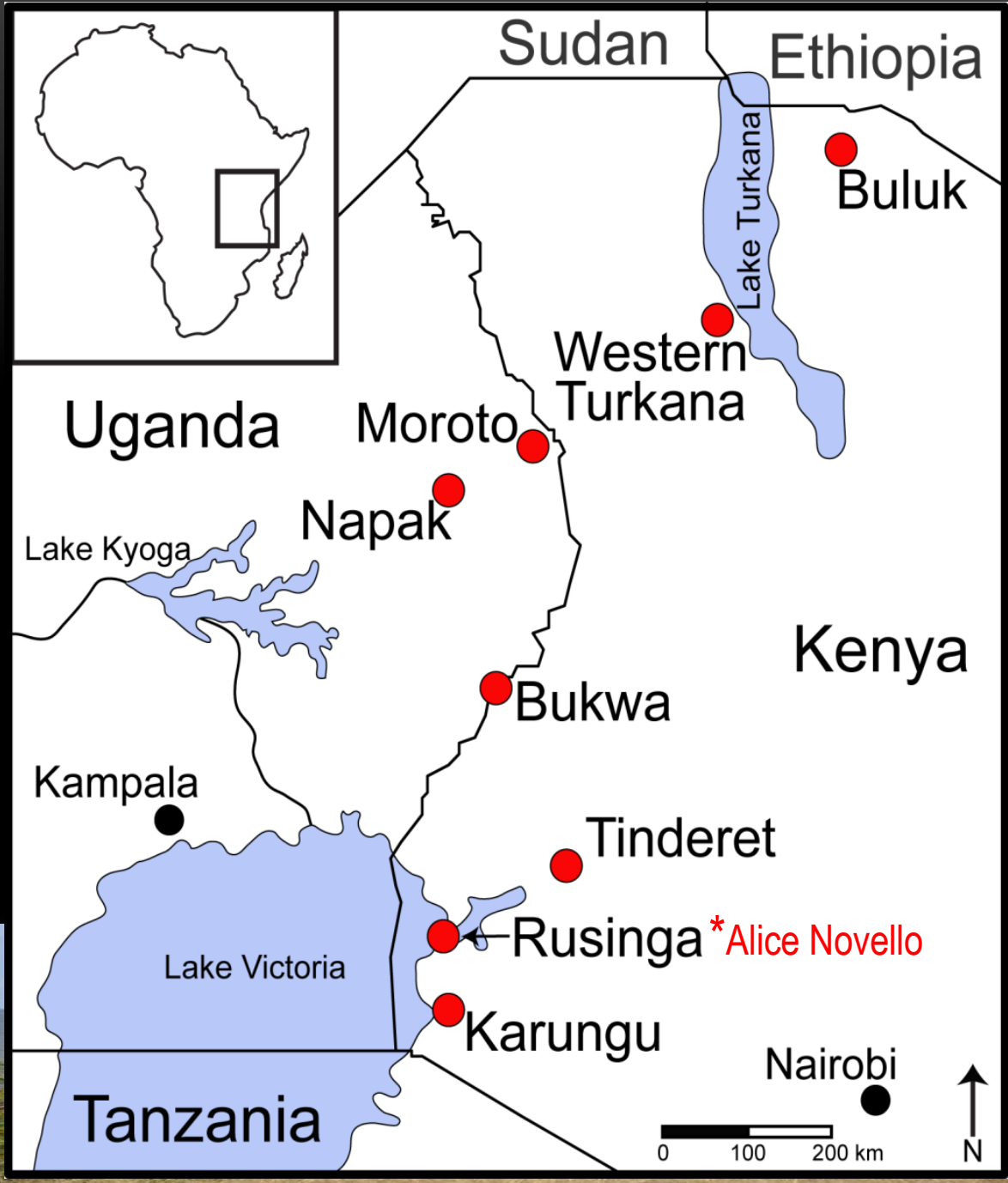




\section{Methods}

1) Field work-

Sampling was carried from various

REACHE project localities in Kenya and Uganda. Participation of local communities have been emphasized
3) Collaborations-

- Alice Novello

- Caroline Stromberg
2) Lab analyses-

Through consultations with key phytolith experts, most effective and efficient protocol (Stromberg et al.,) is being used

\section{4) Publications}

- The ultimate goal is to share our findings with scientific world and local communities 
Methods: key morphotypes
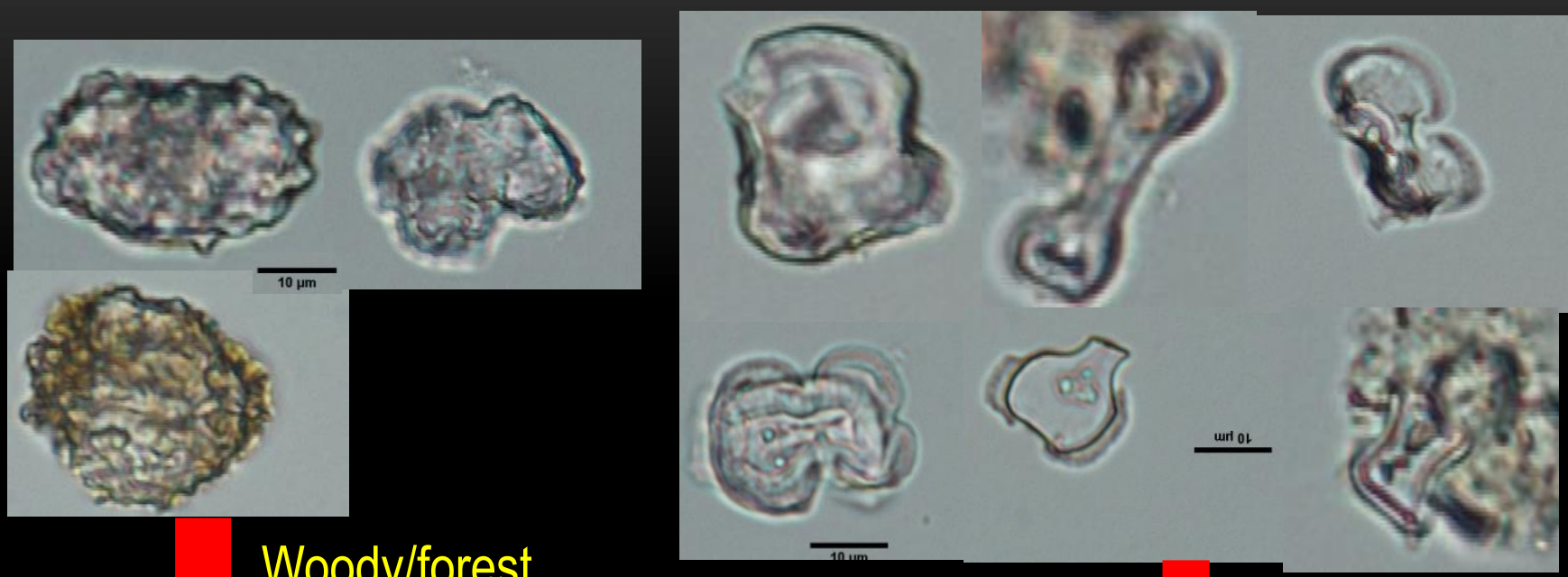

Woody/forest indicators

\section{Grasslands indicators}
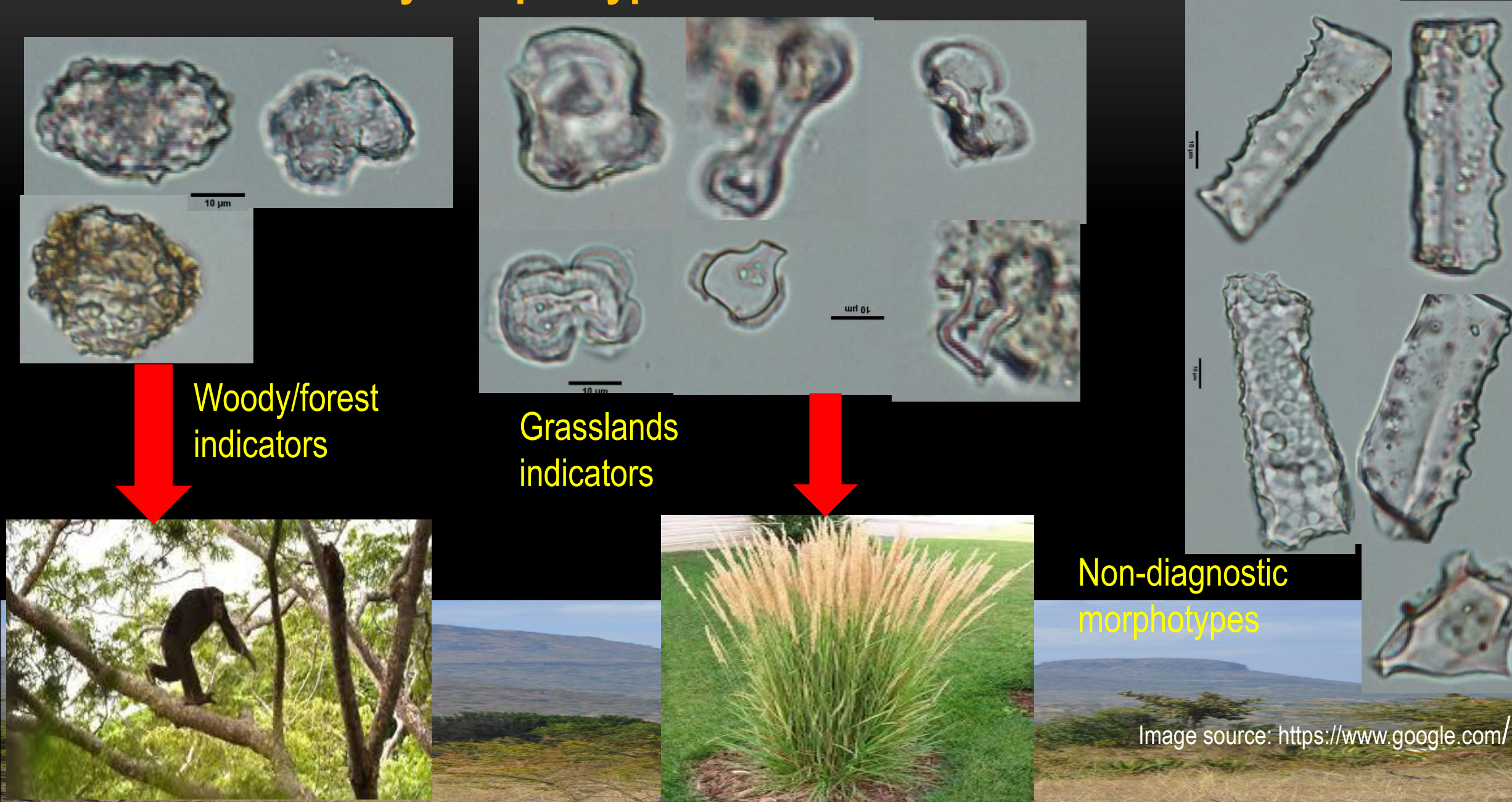

Non-diagnostic
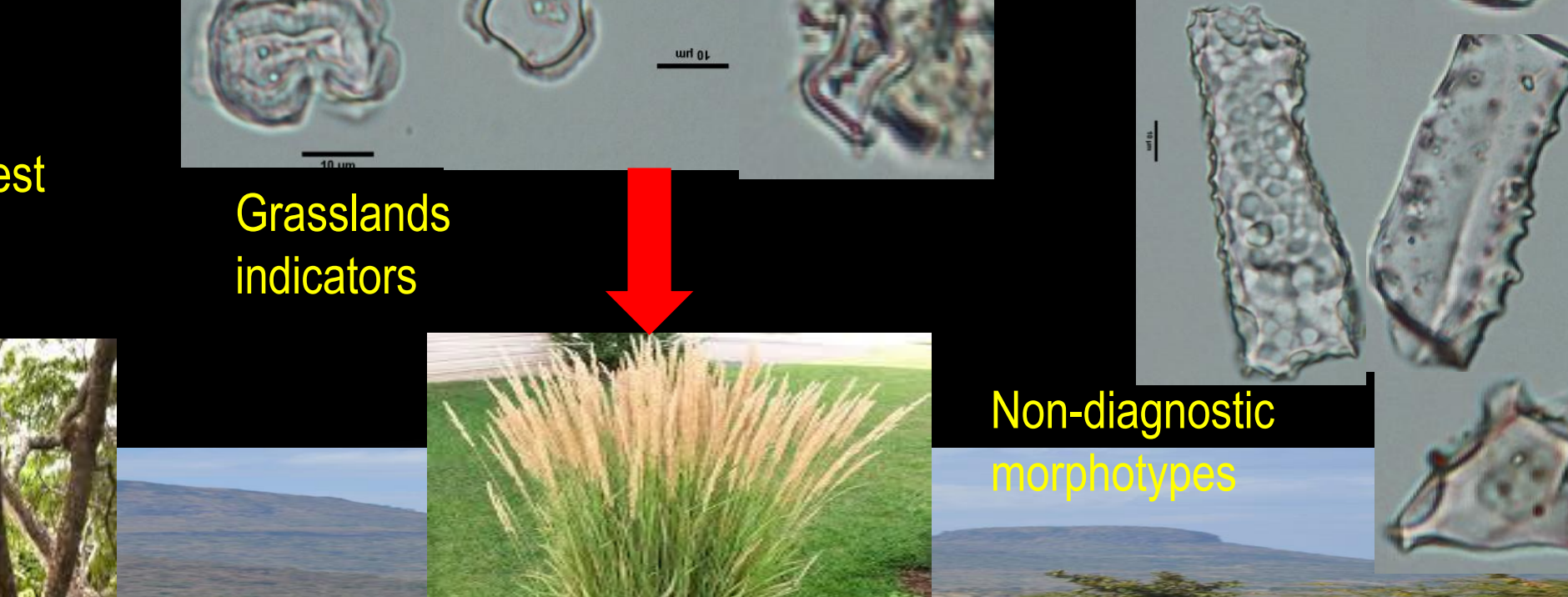

morphotypes

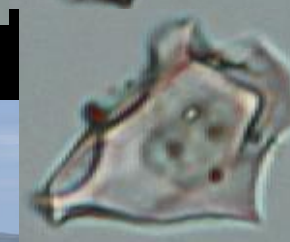




\section{Preliminary results}




\section{Moroto II (ca. 21.2 Ma)}

DP15-08-RK7

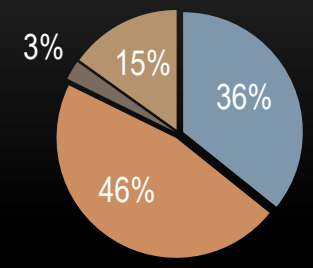

Grass total

$\square$ woody dicots

- Sedge

Others

DP15-07-RK9 (BKII Paleosol $95 \mathrm{~cm})$

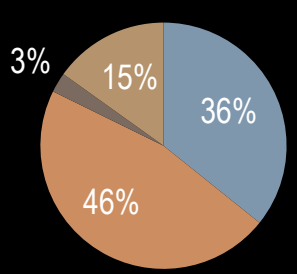

- Grass total

woody dicots

Sedge

u Others
DP15-08-RK20(Bssg. Horizon)

- Grass total

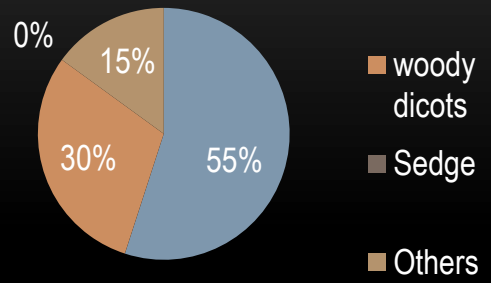

DP15-08-RK22 (Sandy paleosol, 3c Horizon)

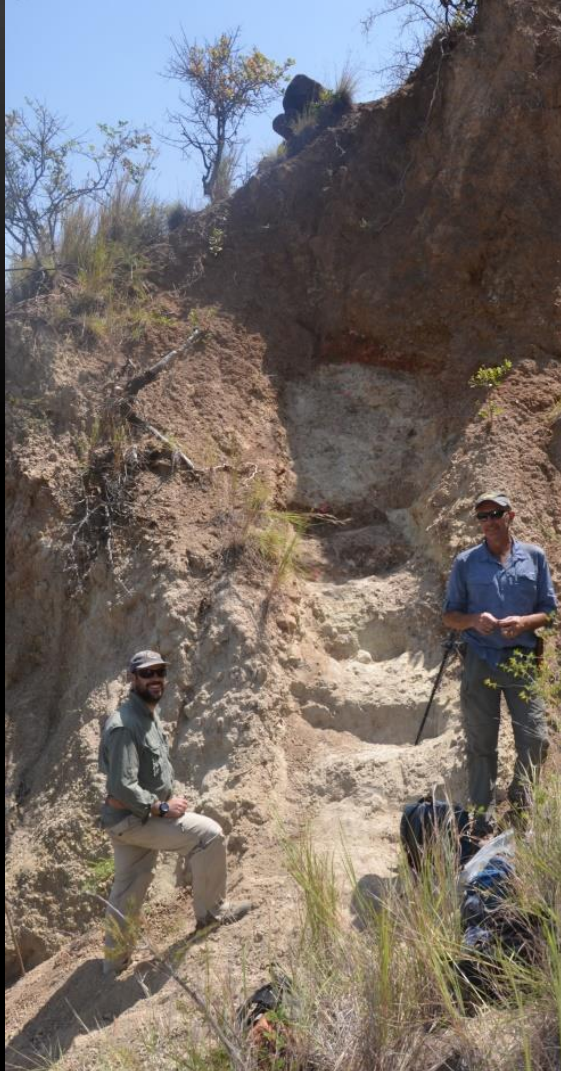

- A total of 12 samples were analysed, all of which yielded significant amount of woody and herbaceous dicots morphotypes.

- However, four sample yielded a significant amount (>20\%) of Grass Silica Short Cells (GSSCs). 


\section{Napak sites (ca. $20 \mathrm{Ma}$ )}

DP15-01-RK1 (Red paleosol Napakl)

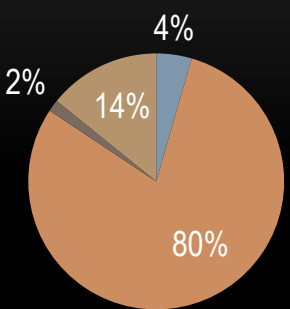

- Grass total

Woody dicots

- Sedges

n Others

DP15-01-RK2 (Green paleosol Napak I

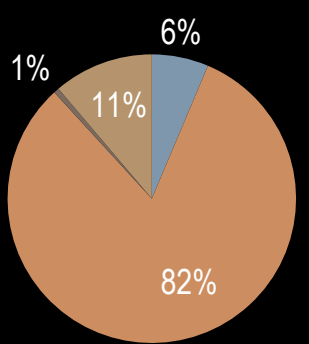

DP15-04-RK6 (DP-04-Paleosol II Napak C-IV)

$2 \% 6 \% \quad 7 \%$

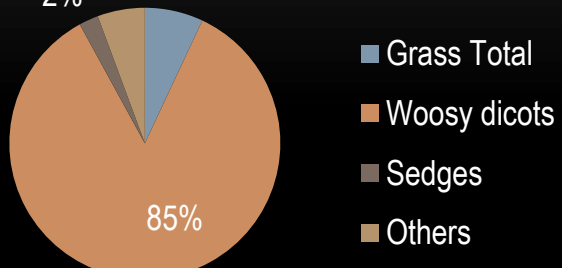

Grass total

- Woody dicots

- Sedges

口 Others
Phytolith assemblages from Napak I and CCIV are dominated with woody dicots. $>80 \%$ of the total assemblage were woody dicots.

GSSCs and sedge morphotypes were rare but present in the assemblage 


\section{Bukwa II( ca. $19 \mathrm{Ma})$}

\section{Bukwa II}

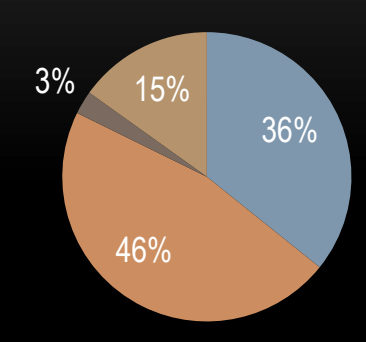

Bukwa II-RK25

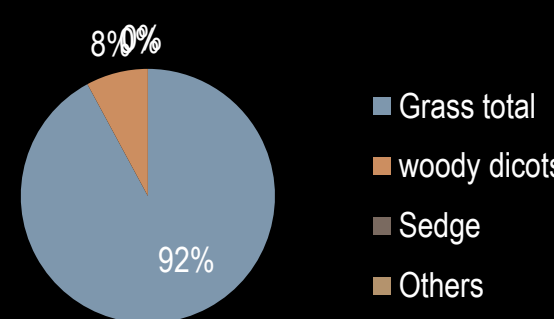

- Grass total

uwoody dicots

$\square$ Sedge

athers

口 Others
Phytolith assemblage is dominated by GSSCs . One sample produced $92 \%$ of the total assemblage

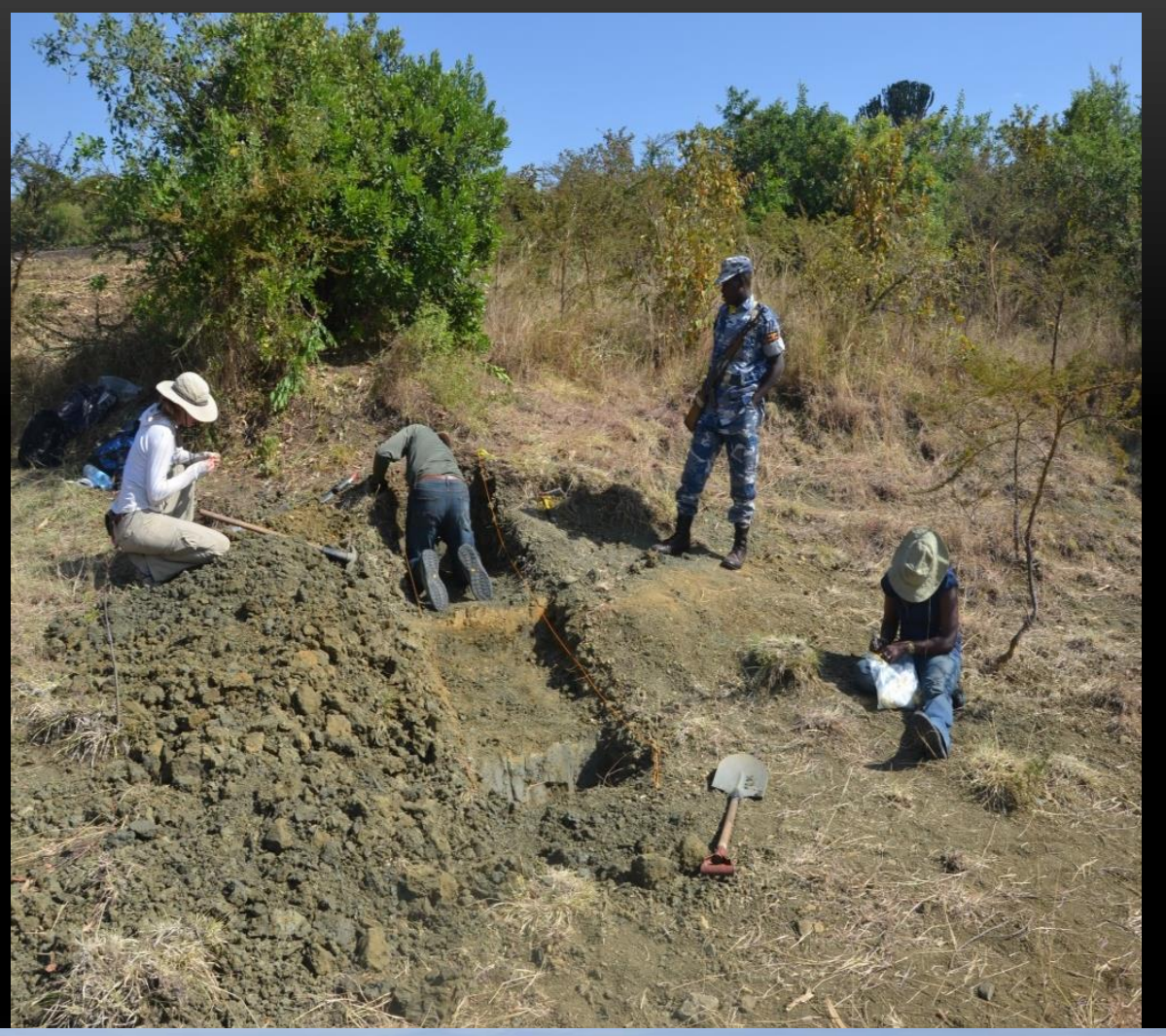




\section{Karungu (ca. 18Ma)}

NG19-B PHY- Ngira Karungu

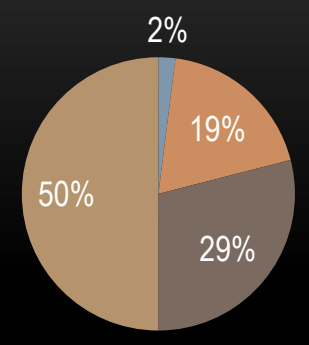

- Grass total

- Woody dicots

n Others

\section{NGR-H1-PHY Ngira, Karungu}

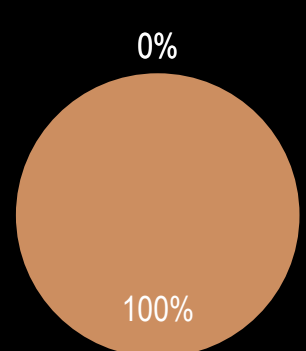

- Grass total

- Woody dicots

O Others
NG5-H3 PHY- Ngira Karungu

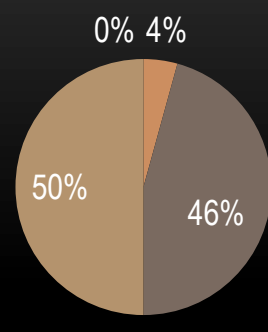

Grass total

- Woody dicots

- Others

NGR-H3-PHY Ngira, Karungu

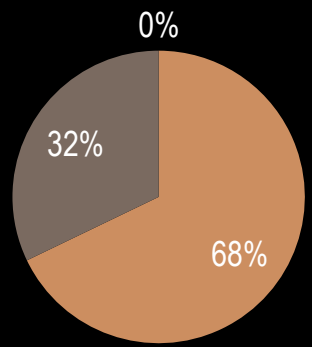

- Of the five samples analysed, four yielded phytoliths

- Grass total Woody dicots

athers
- Phytolith assemblage is dominated by woody indicators.

- GSSCs are absent except the insignificant presence in one sample

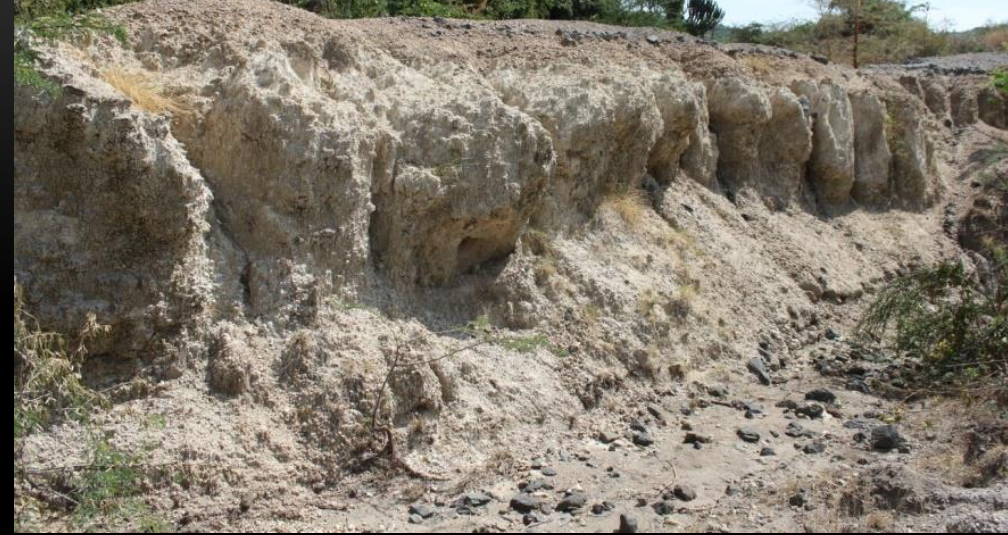




\section{Kalodirr (ca. 17-16 Ma)}

KAL-TP-H1-RK1

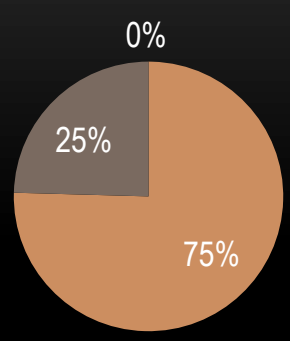

- Grass total

Woody dicots

口Others

KAL-TP-H1-RK2

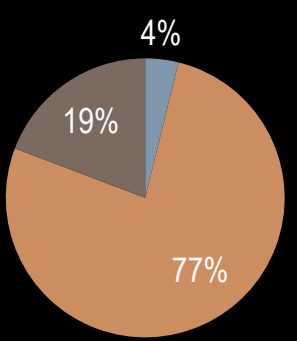

- Grass total

Woody dicots

n Others

KAL-TP-H4-RK2

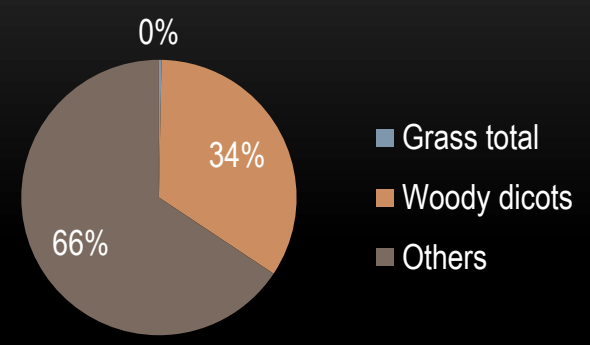

KAL-UG-H1-RK1

- Grass total

- Woody dicots

n Others

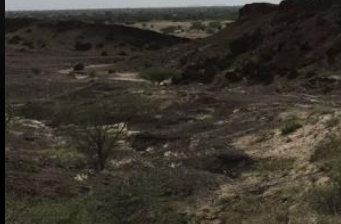

$+2$

- All four samples processed yielded.

- Phytolith assemblage was dominated by woody dicots.

- GSSCs are rare in the sites while sedges are completely absent 


\section{Muororot (ca. 17-16 Ma)}

Mon-H4-RK4 (Muororot)

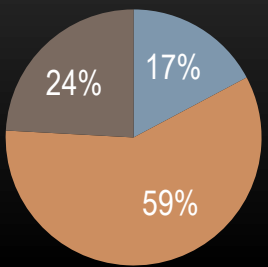

Mon-H9-RK1

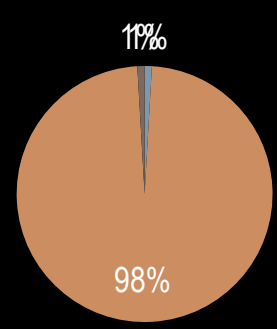

- Grass total

Woody dicots

athers

Mon-H5-RK2

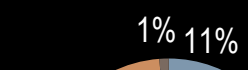

- Grass total

-Woody dicots

口Others
Mon-H6-RK3
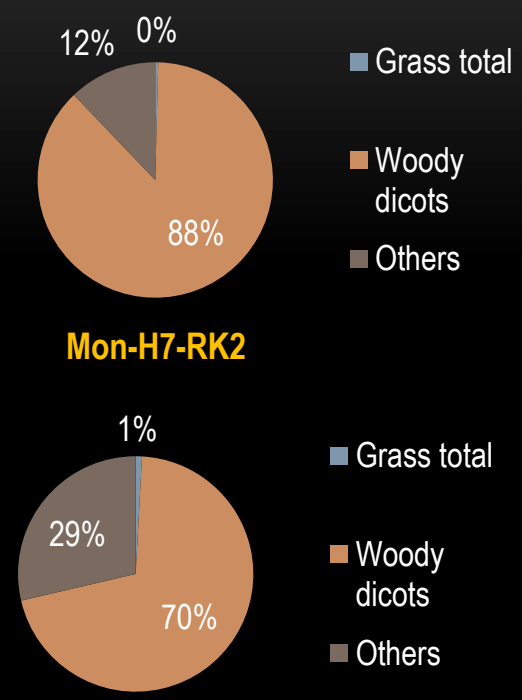

- Grass total

Woody

dicots

口 Others

- Muororot assemblage is dominated by woody indicators.

- Grasses are rare to absent

- $\quad$ Sedges are absent

- Grass total $3 \%$

Mon-H2-RK1

Grase total
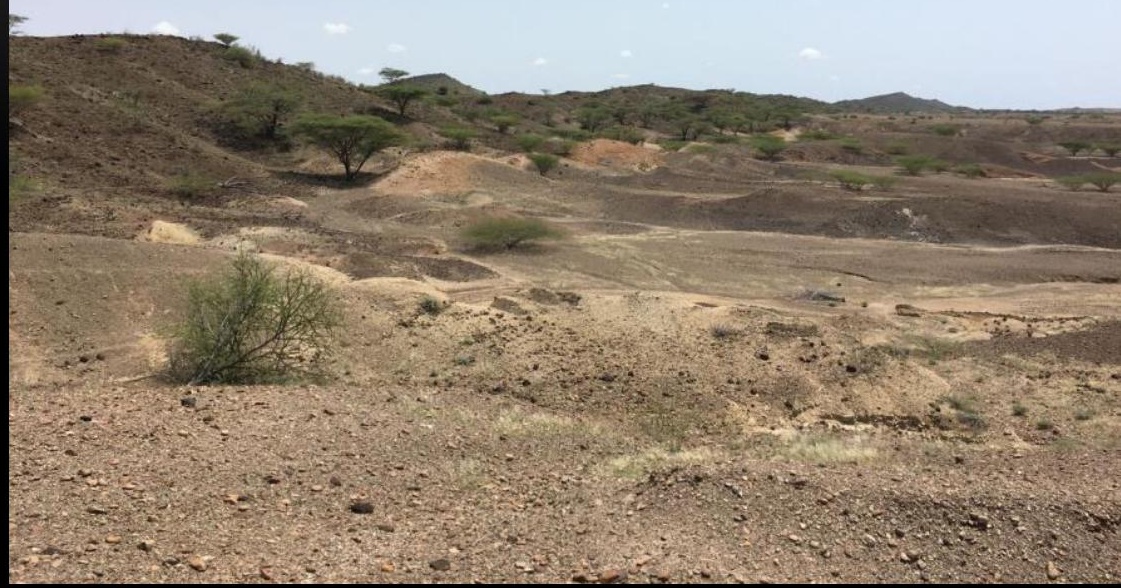


\section{Buluk (17-16 Ma)}

B16-21

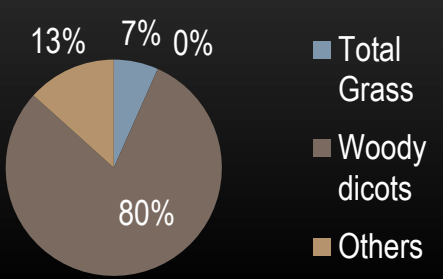

B16-38
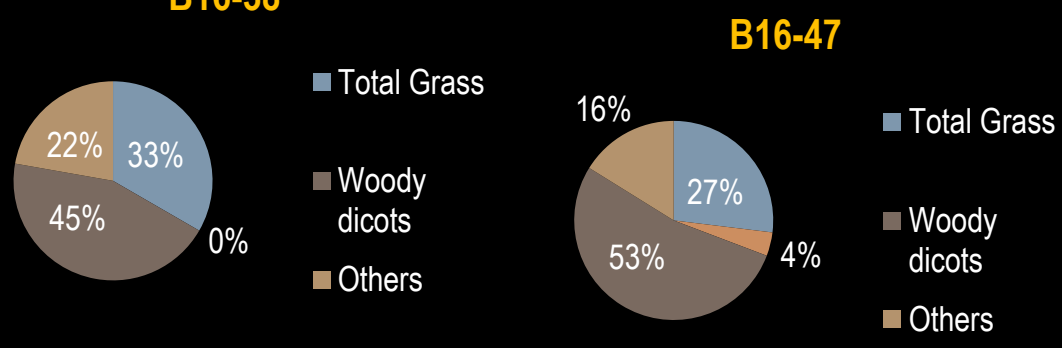

B16-51

$14 \% \quad 7 \% 0 \%$
B16-33

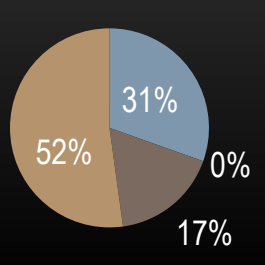

B16-63

Total

$$
\text { Grass }
$$

口 Sedges

Woody

dicots

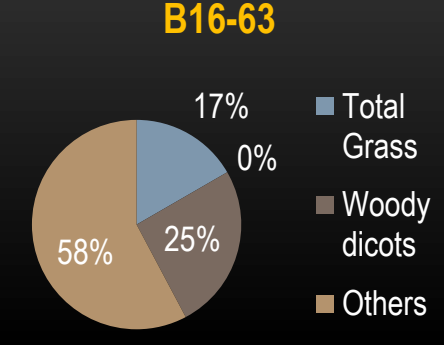

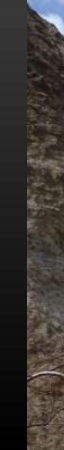

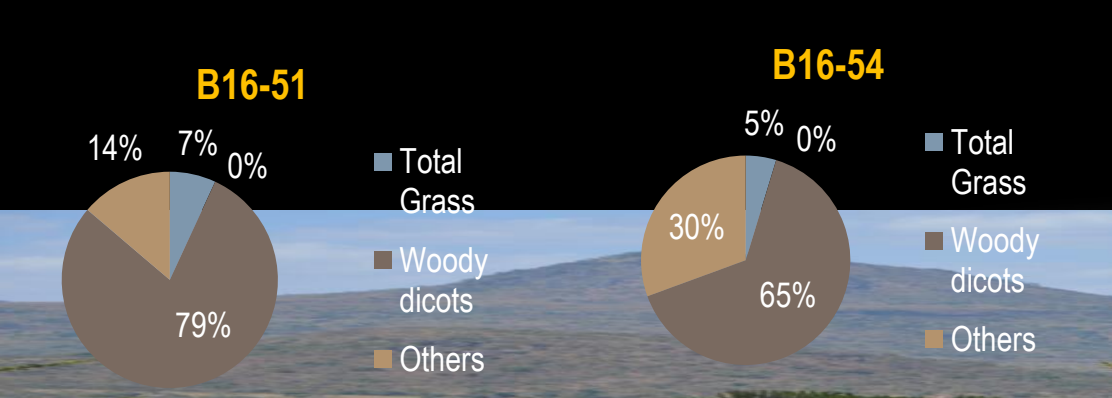

- All seven samples processed yielded phytoliths

- Woody dicot dominate the assemblage

- GSSCs are significantly present in at least in 3 samples $>20 \%$ occurrence.

- Sedges only present in one sample 


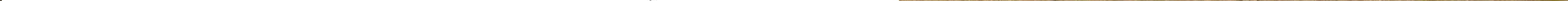


- In summary, these preliminary results suggest varied vegetation structure on the early Miocene landscapes.

- There is a clear indication of presence of $\mathrm{C}_{4}$ grasslands especially in Moroto II (ca. 21.2 Ma) and Bukwa II (ca.18 Ma) in Uganda and Buluk site (ca.16 Ma) in Kenya

- These diverse habitats, may have been as a result of either varied local climatic factors, especially precipitation, or local topographic orientation or both.

- These results corresponds with other data analysed from various proxies such as stable isotopes, palaoe-pedological analyses (REACHE TEAM). 


\section{Acknowledgement}

- Funding

- National Science Foundation (BCS \# 1241807, 1241811, 1241812, 1241817, 1241918, 1053549)

- The Leakey Foundation,

- The Paleo Society

\section{- Collaborating Institutions}

- The National Museums of Kenya

- Southern Methodist University

- Baylor University

- University of Michigan

- University Of Calgary

- University of Minnesota

- Stony Brook University

- Abteilung Paläoanthropologie und Messelforschung, Forschungsinstitut und Naturmuseum.

- Makerere University

- University of Washington

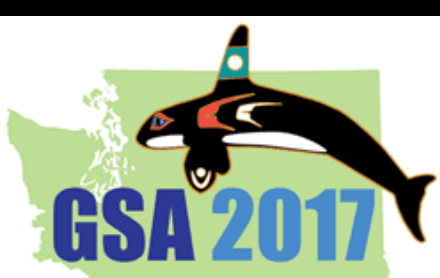




\section{Thank you all for listening (;)}

$3 \times 11^{2}$

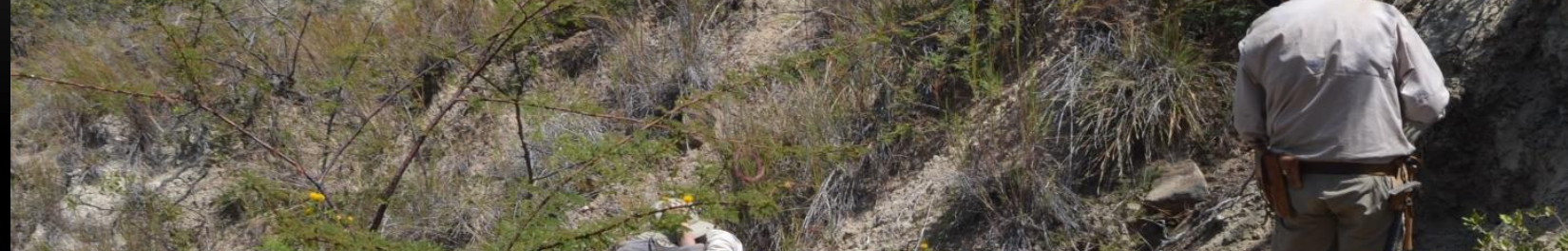

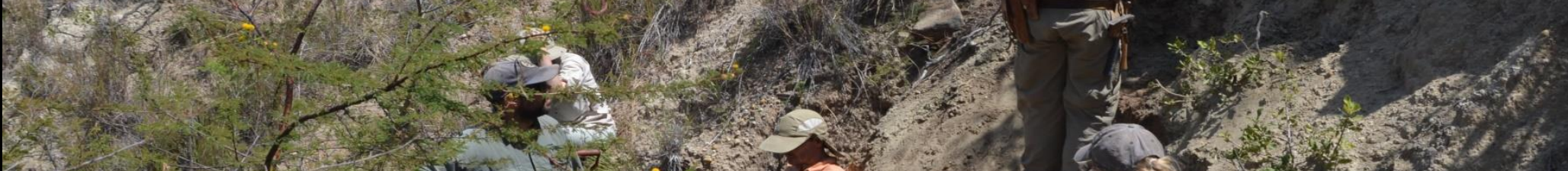
3he

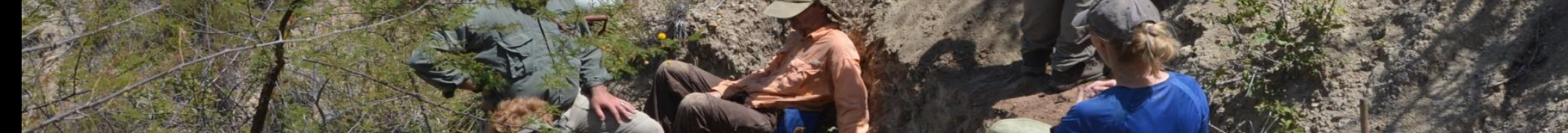

3. 435

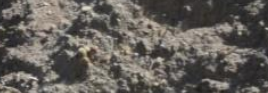

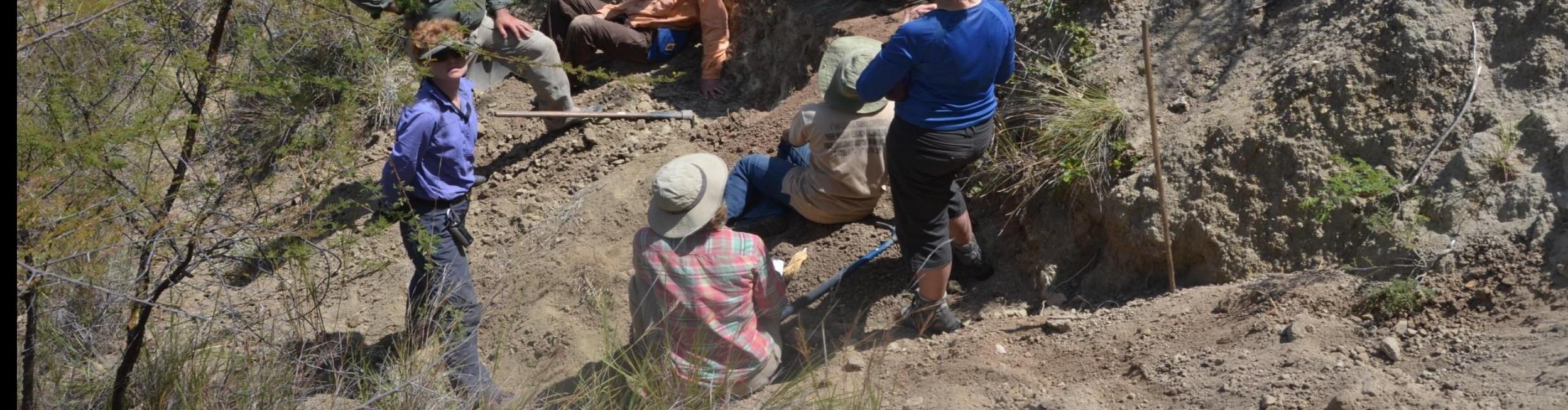

